\title{
Behaviour Tracking: Using geospatial and behaviour sequence analysis to map crime
}

Keatley, D. A..$^{1 *}$, Arntfield, M. ${ }^{2}$, Gill, P. ${ }^{3}$, Clare, J. ${ }^{4}$, Oatley, G. ${ }^{5}$, Bouhana, N. ${ }^{3}$, \& Clarke, D. D. $^{6}$

${ }^{1}$ School of Law, Murdoch University, Perth, 6150, Australia

${ }^{2}$ Faculty of Arts \& Humanities, Western University, London, Canada

${ }^{3}$ Jill Dando Institute, University College London, London, United Kingdom

${ }^{4}$ School of Law, University of Western Australia, Perth, 6009, Australia

${ }^{5}$ School of Science, Engineering, and Information Technology, Federation University Australia, Melbourne, Australia

${ }^{6}$ School of Psychology, University of Nottingham, NG72RD, United Kingdom

*Correspondence Author: Dr David Keatley, Researchers in Behaviour Sequence Analysis, School of Law, Murdoch University, Perth, 6150, Australia. Email:

David.Keatley@murdoch.edu.au 


\begin{abstract}
Crime is a complex phenomenon. To understand the commission of crime researchers must map both the temporal and the spatial processes involved. The current research combines a temporal method of analysis, Behaviour Sequence Analysis, with geospatial mapping, to outline a new method of integrating temporal and spatial movements of criminals. To show how the new method can be applied, a burglary scenario was used, and the movements and behaviours of a criminal tracked around the property. Results showed that combining temporal and spatial analyses allows for a clearer account of the process of a crime scene. The current method has application to a large range of other crimes and terrorist movements, for instance between cities and movements within each city. Therefore, the current research provides the foundation framework for a novel method of spatiotemporal analyses of crime.
\end{abstract}

KEYWORDS: crime; burglary; Sequence Analysis; geospatial anlaysis; methods 


\section{Behaviour Tracking: Using geospatial and Behaviour sequence analysis to map crime}

Crimes do not happen in a vacuum, distinct and separate from surrounding actions,

3 events, and locations. To understand the full crime process, from inception through to

4 commission and escape from location, a dynamic method is required. Researchers have

5 developed a number of methods to analyse the temporal dynamics of different crimes, providing

6 investigators with a deeper understanding of the processes involved (Keatley, 2018; Keatley,

7 Barsky, and Clarke, 2017; Taylor et al., 2008). In addition, geospatial research has provided

8 insight into the movements of criminals through space (Ratcliffe, 2010; Chainey and Ratcliffe,

9 2013). The combination of temporal and geospatial analysis, however, can provide investigators,

10 security consultants, and Law Enforcement Organisations (LEOs) with an opportunity to gain

11 more insight into the commission of a crime, and therefore, places of intervention (Keatley,

12 2018). The current research provides a novel analytical approach to integrating temporal and

13 geospatial data: Behaviour Tracking.

Burglary is a complex phenomenon that is often overly-simplified (i.e., breaks-enters-

15 steals-leaves sequences) in the research literature (Arntfield, 2016; Keatley, 2018). Of course,

16 burglary is far more nuanced and involves multiple behaviours both temporally and spatially.

17 Residential burglaries, for example, can progress and develop into a number of further criminal

18 behaviours such as where an offender targets dwellings at night for the purpose of accessing or

19 voyeurising the occupants while they sleep, as well as confronting the victims (Arntfield, 2017).

20 This type of burglary, one recently highlighted with the belated arrest of alleged prowler, rapist,

21 and serial killer James DeAngelo in the 'Golden State Killer' cold case burglary-murders is just

22 one of six recognised subtypes of residential burglaries that have an often overlooked sexual or

23 fantasy motivation rather than a financial one (Kosir and Drake, 2012). This would in part 
1 explain why burglary is also over-represented as a first criminal conviction among violent (both

2 homicidal and non-homicidal) sex offenders (Beauregard, et al. 2017). In other words, it would

3 appear as though burglary has been historically misunderstood as being solely a petty or

4 property-oriented crime and its more paraphilic and predictive dimensions overlooked. The

5 Behaviour Tracking method proposed in the current research allows researchers to investigate

6 and analyse crime in terms of temporal and spatial approaches.

The concept for this integration originally came from applied work conducted by the

8 authors on the movements of police officers about a city through known hot spots and crime

9 zones. The same method is outlined in the current paper, related to a burglary scenario as proof

10 of concept. A burglary was chosen as it provided a relatively contained incident, with clear,

11 thorough data that were not ambiguous, and therefore showcased the method in the current

12 research ${ }^{\mathrm{i}}$. Although the data used in the current study were taken from a sample of participants,

13 rather than real-world data, the rationale is because the focus of the current manuscript is on

14 elucidating the Behaviour Tracking method, first and foremost. Evidently, real-world data is

15 'messier' (in terms of steps in sequences being missing); however, the use of a perception dataset

16 in the current study showcases the Behaviour Tracking method. In real-world research, involving

17 sequences that may have missing parts, the method is still useful in two ways: first, by acting as a

18 prompt to investigators, witnesses, or suspects about which parts of the sequence they may be

19 missing or overlooking (Keatley, 2018); second, because in real-world contexts steps in

20 sequences that are missing are not systematic across the entire sample. For example, if sequence

211 has the chain: $\mathrm{A} \rightarrow \mathrm{B} \rightarrow \mathrm{D} \rightarrow \mathrm{E}$ (where each letter refers to a behaviour), and sequence 2 has the

22 chain: $A \rightarrow B \rightarrow C \rightarrow D \rightarrow E$, then we can still see the 'missing' behaviour in other sequences. To 
1 date, there is no standard of minimum sample required (Keatley, 2018); however, it is clear that a

2 larger sample will reduce the possibility of missing data misguiding final analyses.

The Rational Choice Perspective (RCP; Clarke and Felson, 2004; Cornish and Clarke,

4 2016) also provides a theoretical underpinning for the current research approach. A criminal's

5 decision making process and behaviours are the result of complex interactions with the

6 environment they are in. To understand a crime, therefore, means to map the commission of a

7 crime in terms of physical and temporal space and interactions. In this perspective, a criminal's

8 behaviour is purposive and rational; though precipitators may also affect the likelihood of certain

9 behaviours (Leclerc, Wortley, and Dowling, 2016; Wortley, 2016). Furthermore, RCP outlines

10 that crimes occur in sequential stages (Leclerc and Wortley, 2013). The RCP has been a

11 theoretical framework for a variety of different crimes, from school shootings (Keatley, McGurk

12 and Allely, 2018), to terrorism (Gilmour, Hicks and Dilloway, 2017), sexual assault and rape

13 (Leclerc and Wortley, 2013), and theft (Homel, Macintyre and Wortley, 2014). While the

14 decision making process for different crimes may be crime-specific, the general approach to

15 understanding criminals behaviours using RCP can be applied across crimes. An added benefit

16 using RCP to understand the behaviours and decisions of individuals in a crime, is that the same

17 approach can be used to understand victims' responses. For instance, in a fire or terrorist event,

18 victims have the central goal of fleeing or escaping unharmed; therefore, we can begin to

19 understand the motivations of individuals within the scene, and map their behaviours using the

20 Behaviour Tracking technique outlined here in the case of burglary. A hypothetical scripting

21 approach is used in the current research as this has previously been used in temporal methods,

22 such as Crime Script Analysis (Caneppele and Calderoni, 2013; Carroll and Payne, 2014;

23 Leclerc and Wortley, 2014; Haelterman, 2016). The use of hypothetical scripts also allows data 
1 to be developed that are similar to real-world data (i.e., police interviews/interrogations), while

2 not breaching privacy and nondisclosure agreements.

Mapping the temporal commission of burglary provides researchers and investigators with the first step towards understanding the crime commission in more detail and perhaps

5 seeing key choice or intervention points ${ }^{\mathrm{ii}}$. Behaviour Sequence Analysis (BSA) is a useful

6 method for categorising and analysing the sequential pattern of behaviours (Bakeman and

7 Gottman, 1986; Clarke and Crossland, 1985; Ivanouw, 2007; Keatley, 2018). BSA shows

8 patterns in complex data by analysing the statistical dependencies between behaviours over the 9 course of a time period (e.g., a burglary). BSA is a three-stage method, starting with the parsing

10 of behaviours. Police reports, for example, are typically qualitative accounts of the crime, which

11 require breaking down or separating into individual behaviours and events. In the second stage,

12 behaviours are categorised according to a classification system and coded together. For example,

13 "breaks-in via back door" and "breaks and enters through rear door" can both be categorised as

14 Behaviour $A$. Inter-rater agreement is used to ensure behaviours and events are categorised

15 consistently, typically resulting in a behaviour coding key. The final stage of BSA involves the

16 analyses of transitions between behaviours. The development of an appropriate coding system or

17 framework is therefore an important part of BSA, such that it captures all behaviours under

18 consideration, and that they are suitably distinct.

Complex actions and interactions can be analysed to show likelihood of transitions

20 between behaviours (Ivanouw, 2007). In the simplest form of BSA, called a lag-one sequence

21 analysis, transitions are calculated between behaviours (e.g., breaks glass, moves object) or

22 events (e.g., alarm raised) that directly follow each other. In simple terms, the analysis shows

23 the likelihood, compared to chance, of $A$ leading to $B$, and $B$ leading to $C$ and so on. In terms of 
1 burglary, BSA can show the likelihood of breaking-in through the rear door (category $A$ ) and

2 then proceeding to steal things from the dining room (category $B$ ) or the living room (category

$3 C$ ). Therefore, BSA shows investigators whether $A \rightarrow B$ is more likely than chance, compared to

$4 A \rightarrow C$. These behavioural chains are developed into much more complex patterns of behaviour.

5 Clearly, Behaviour Tracking is based on BSA approaches; however, the end result of typical

6 BSA is to create a state transition diagram (a diagram showing the chains of behaviours across a

7 sample). In Behaviour Tracking, including geographic information in a state transition diagram

8 would lead to a complex array of sequences (as chains lead back and forth). Furthermore, it

9 would not be clear how and where to position a spatial location into a sequence, as multiple

10 behaviours could occur in one location. Therefore, the benefit of the Behaviour Tracking method

11 is to take the spatial data and use it to plot a state transition map, which more clearly outlines

12 movements and behaviours throughout different locations.

13 Behaviour Sequence Analysis (BSA) has been previously used to examine a number of

14 criminal Behaviours and activities, including: serial killers' life histories and murders (Keatley et 15 al., 2018); drink-driving (Keatley, Barsky and Clarke, 2017); violent episodes between people

16 (Taylor, Keatley, and Clarke, 2017); perceived (Ellis, Clarke and Keatley, 2017) and actual rape

17 cases (Fossi, Clarke and Lawrence, 2005; Lawrence, Fossi and Clarke, 2010). In addition to the

18 statistical analysis of Behavioural chains, BSA also provides state transition diagrams to provide

19 visual illustration of the chains of Behaviours. The state transition diagrams are simplified

20 models of the larger transition frequency matrices, and are typically organised in top-down

21 sequential representations. The current research will develop the spatio-temporal Behaviour

22 Tracking in terms of burglaries. This is the first step towards developing an integrated method of 
1 investigation that incorporates analysis from BSA and more widely used geographic, and geo-

2 spatial analysis in criminal contexts.

3 Given the novel nature of the present research, no formal hypotheses were made

4 regarding the sequence maps. However, based on previous research in the field, a number of

5 behaviours are likely to occur in the current data. Therefore, a number of expectations can be

6 made, a priori. First, sequences are likely to begin with entry to the premises from the rear - this

7 is likely to reflect awareness that burglars attempt to avoid detection (Cornish and Clarke, 1987;

8 Osborne and Capellan, 2017). Furthermore, it is likely that perceptions of burglar's actions will

9 follow rational sequences. Behaviours such as attempting to avoid detection (i.e., wearing

10 gloves; entering properties through rear windows and doors) are likely to occur, similarly, being

11 selective over which items are stolen (based on value and ease of movement with objects) are

12 likely to influence or guide perceptions of burglar's decision making and Behaviours (see

13 Wellsmith and Burrell, 2005). The current research also builds on other 'virtual reality' research

14 in the area of burglary (Nee and Taylor, 2000; Pastra, Saggion and Wilks, 2003; van Gelder et

15 al., 2017). Therefore, while the current research uses participants' perceptions of burglaries, a

16 number of typical behaviours are still likely to occur. While the main focus of the current

17 research is to show a new method for Behaviour Tracking, the results can also be used to inform

18 and support existing and future research in the area of burglary.

\section{Method}

\section{Participants}

Full access to police records of crimes are typically restricted both in terms of access,

22 and then publication once access is granted. Therefore, the current study used a sample of 41 
1 participants (26 females, 15 males, $M_{\text {age }}=21.39, S D=3.67$, range $=19-40$ years) to provide data

2 similar to that found in police reports and suspect statements. Participants were selected based on

3 having awareness and understanding of burglaries in the UK. Participants were asked if they had

4 been victims of burglary. The majority of participants $(n=35)$ were students on a Forensic

5 Psychology course ${ }^{\mathrm{iii}}$, which had covered various types of crimes including burglary. Therefore,

6 participants were not naïve to burglaries or typical behaviours performed by burglars. All

7 participants gave fully informed consent to participate and for their data to be analysed. The

8 Ethics Review Board at the University of Lincoln approved the current study.

\section{Data}

The data consisted of 41 first-person statements taken from participants regarding their

11 perceptions about the particular movements and behaviours an individual would perform while

12 burgling a house. In order to allow more focused accounts, participants were provided with a

13 floor plan of a single-story, ground-floor residential property, which had detailed information

14 about rooms and items in them (see Figure 1) ${ }^{\text {iv }}$. Participants were told to give a first-person

15 account of a person's movements and behaviours as they burgled a house, similar to police

16 interrogating a burglar about their actions. Participants were encouraged to be as detailed as

17 possible about all movements and behaviours they would make, so that the analyses could be

18 more detailed with no gaps in the chains - which is similar to police directives in an

19 interrogation to provide detailed accounts. Clearly, participants may not include all information,

20 the same as witness/suspect statements may not; however, this is reduced through the BSA

21 approach (Keatley, 2018). Participants were told the house was empty when burgled, and the

22 burglary occurred at night to avoid possibly entering into mapping sexually-motivated burglaries. 
2 they were detailed enough to allow for BSA - typically this means 3 or more individual

3 Behaviours (Keatley, 2018). In the current dataset the average length was $17.78(S D=4.30$,

4 range $=11$ to 30$)$.

Figure 1. Floor-plan of property being burgled

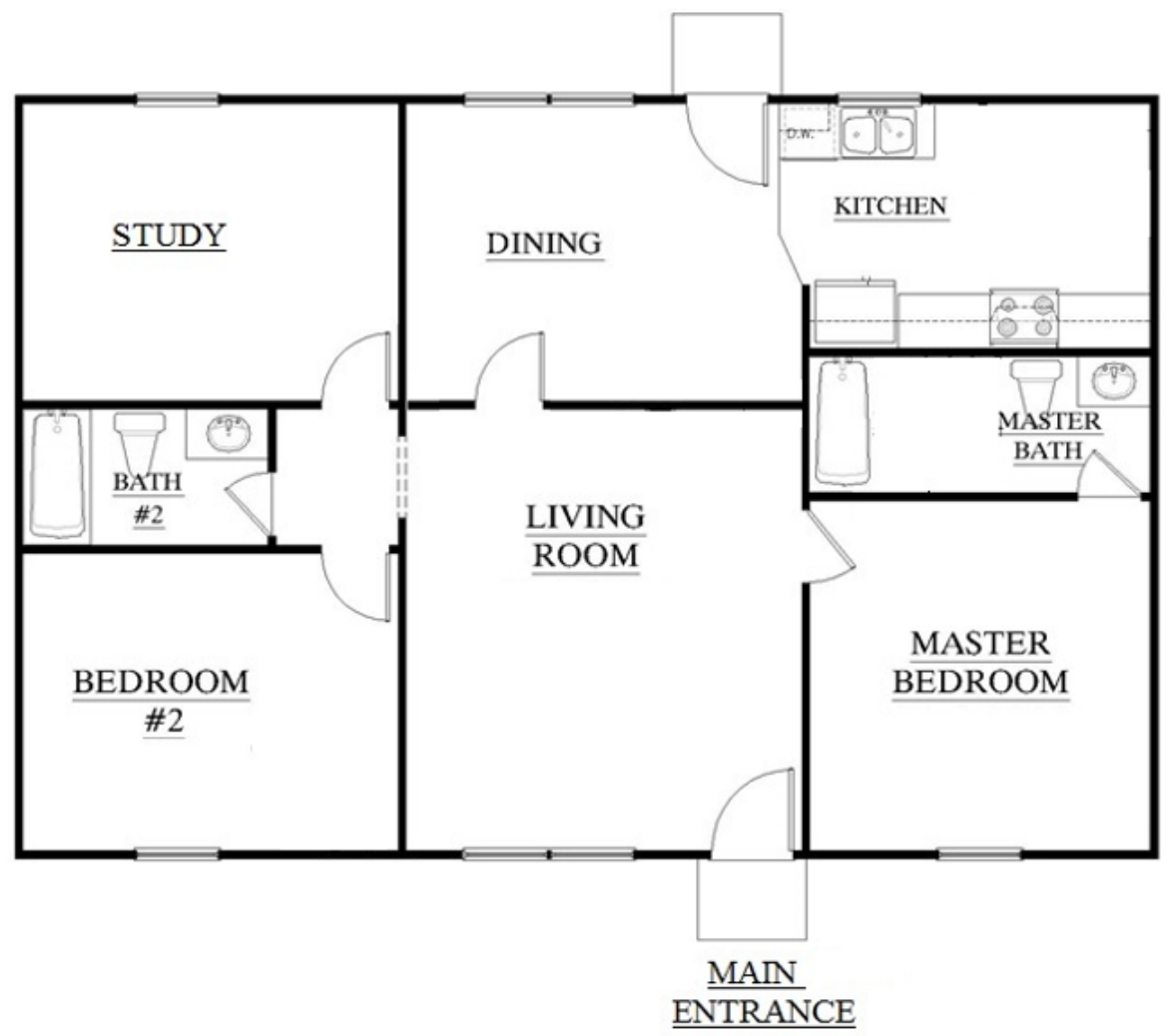

\section{Brief \\ Inventory}

\section{Dining}

Silverware

Living Room

42" TV

Playstation 4

Assorted DVDs

iPAD

\section{Study}

Desktop Computer Laptop Computer

Printer

Master Bedroom

TV

DVD Player

\section{Bedroom 2}

TV

Xbox 360

iPOD 
1 exhaustive (Bakeman and Gottman, 1986; Bakeman and Quera, 2011), which is a pre-requisite

2 for BSA, to ensure there are no gaps in sequence chains and no overlaps. Multiple coders with

3 experience in BSA research developed and agreed on the coding scheme used to categorise

4 statement transcripts ${ }^{\mathrm{v}}$. The coding process was iterated until full agreement and reliability was

5 found. Given the straightforward nature of the case and presentation of materials, there were no

6 ambiguous cases or categories. Finally, a back-translation process was used to recreate

7 statements from codes and check that all important information was still present (Ellis, Clarke

8 and Keatley, 2017). The back-translation approach takes the coded sequence (e.g.,

$9 \quad \mathrm{~A} \rightarrow \mathrm{B} \rightarrow \mathrm{C} \rightarrow \mathrm{D})$ and turns it back into real behaviours. The reformed behaviour sequence is then

10 compared to the initial participant statement and researchers agree on whether it closely matches

11 the essence and outline of the original sequence without undue loss or biasing. This was the case

12 for all sequences in the current sample.

\section{Statistical Analysis}

After statements were coded into sequence chains, data were input into a statistical

15 package R (R Team, 2013), and a program was used to analyse the transition frequencies and

16 standardised residuals. This analysis gave a transition frequency matrix of all significant

17 transitions from antecedent to sequitur. In order to make results more easily interpretable, these

18 transitions were graphically presented in a behaviour map. However, a novel development in the

19 current research is to include spatial place-markers in the sequences, which allow for the state

20 transition diagram to be positioned in a spatially meaningful state space. Instead of simply

21 placing the nodes of the state transition diagram sequentially top-down from start to finish, the

22 nodes were placed spatially in the state space according to locations in the property. Therefore,

23 the current research not only maps temporal progression through the property; but, also spatial 
1 movements. BSA also accounts for chance, through Chi-Square statistics and standardised

2 residuals; therefore, it is not simply the total number of transitions (movements from one room to

3 the next and actions therein), but also how likely an offender is to move around a house and

4 perform certain actions, compared to chance.

\section{RESULTS}

8 individual Behaviours and events. Frequency results indicate how closely the current dataset

9 match known or existing datasets, it also provides a first glimpse of the type of individual

10 Behaviours and their prevalence in the current dataset. Table 1 shows the frequency of rooms

11 mentioned in reports, and the items stolen in each room.

13 Table 1. Frequency of individual categories

\begin{tabular}{lr}
\hline Category & Frequency \\
\hline Living room & 108 \\
Dining room & 79 \\
Back door & 59 \\
Study & 39 \\
EXIT & 41 \\
Same exit & 36 \\
Bedroom2 & 35 \\
iPAD & 34 \\
Laptop computer & 32 \\
Playstation 4 & 31 \\
Xbox 360 & 30 \\
iPOD & 26 \\
Master bedroom & 23 \\
Silverware & 16 \\
Surveil property & 13 \\
42" TV & 12 \\
DVD player & 11 \\
Assorted DVDs & 11 \\
Desktop computer; Kitchen & 10
\end{tabular}


Different exit; Jewellery/watches etc $\quad 9$

Study window; Wear gloves $\quad 7$

Kitchen window $\quad 6$

Main door; TV (MB); TV (BR2) 4

Dining window; Bedroom window; Printer; Bathroom2 3

Check for open door/window; Wear mask; Wipe fingerprints 2

Master bedroom window; Monitor; Cyber crime; Check house for 1

1 occupants

The frequency table clearly shows that the living room was the most frequented place in

6 potential items to steal. In terms of items being stolen, smaller items were mentioned more

7 frequently, such as iPad $(n=34)$ and laptop $(n=32)$. Finally, while all burglars exited the

8 premises, the majority exited through the same location they entered the building $(\mathrm{n}=34)$.

In order to make the frequency table easier to read, the frequency of movements were

10 mapped on to the property, this is the first step towards mapping movements throughout the

11 property (see Figure 2). Figure 2 shows the main rooms entered, and the main mode of entry and

12 exit: the rear door of the house. For clarity, routes from each room to exit is not mapped on

13 Figure 2. While the frequencies of movements into, around, and out of the property provide some

14 initial awareness of how burglars may move around, it is important to know which of these

15 movements are occurring above the level of chance. For instance, it may be that individuals

16 could randomly move around a property, and by chance end up in one of several rooms.

17 Therefore, to account for chance, BSA was conducted on the chains of movements. 
1 Figure 1. Frequency of movements around the property

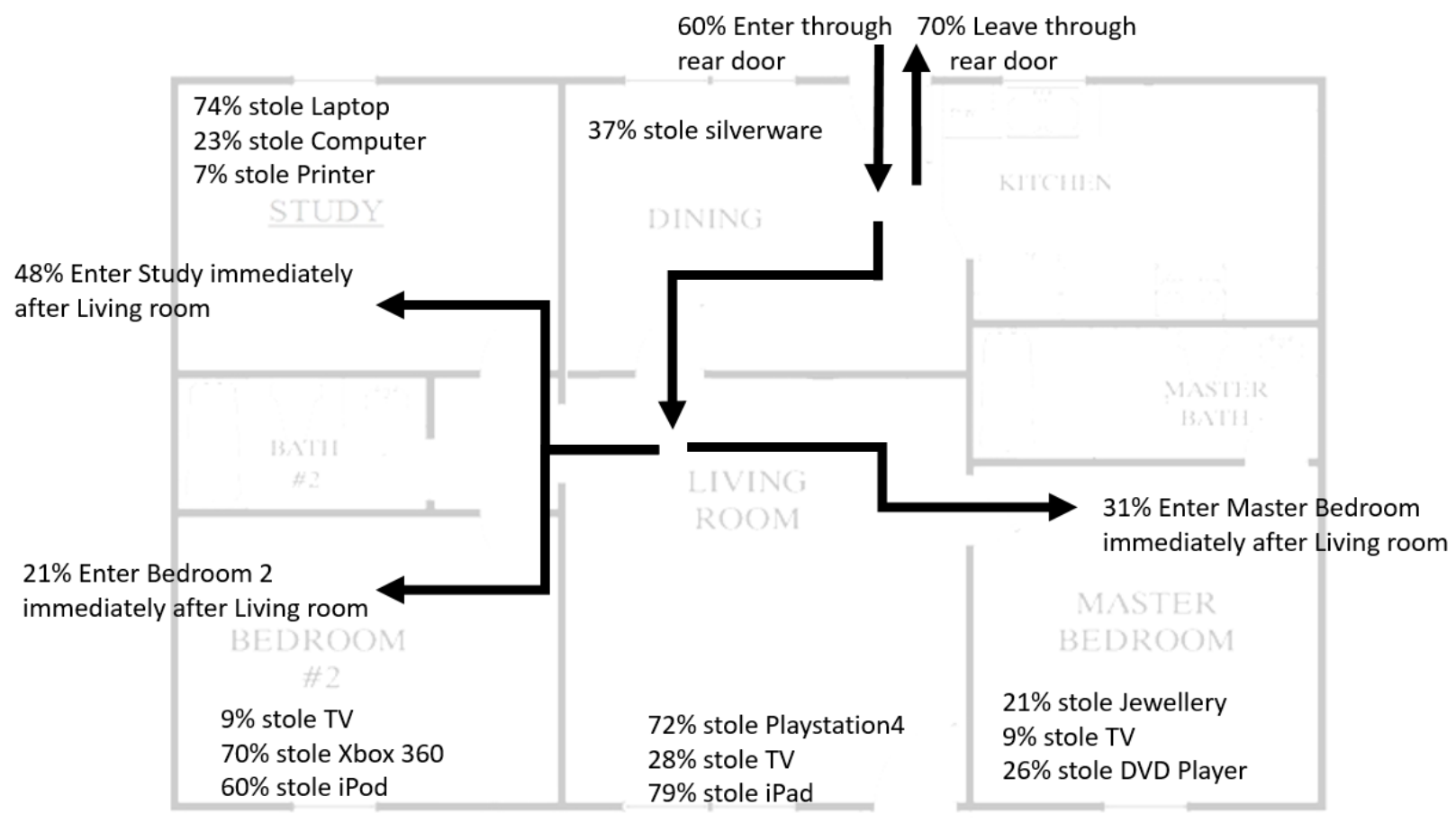

\section{Behaviour Tracking}

A lag-one BSA was conducted on the data, to show the transitions of movements and

7 actions in the perceived commission of a burglary. Transitions between all behaviours in the

8 participants' sequence chains were analysed, and transitions occurring more than would be

9 expected by chance, according to Chi-Square analysis $\left(\chi^{2}\right)$, were plotted. Two state transition

10 diagrams are included, to show how the analyses can be used to investigate different information

11 at different levels of complexity ${ }^{\mathrm{vi}}$. In both diagrams, thicker lines indicate larger standardised

12 residual scores.

13 In Figure 3, only transitions between rooms are included, to reflect the movement of

14 burglars around the property. This is a rudimentary form of analyses, and is included only to 
1 illustrate how the complexity of these diagrams can be increased or decreased to focus on certain

2 crime-scene specific information (for example, this type of analyses could reflect escape paths in

3 other datasets). The transitions clearly show that the dining room is the last room to be used

4 before 'exit' $(\mathrm{n}=24, \mathrm{SR}=10.15)$, and that most exits occurred through the back door $(\mathrm{n}=27$,

$5 \mathrm{SR}=14.08)$. Conspicuous by their absence of inclusion in the diagram is the master bathroom

6 and second bathroom (bathroom \#2) ${ }^{\mathrm{vii}}$.

8 Figure 2. Transition of movements around the property (locations only)

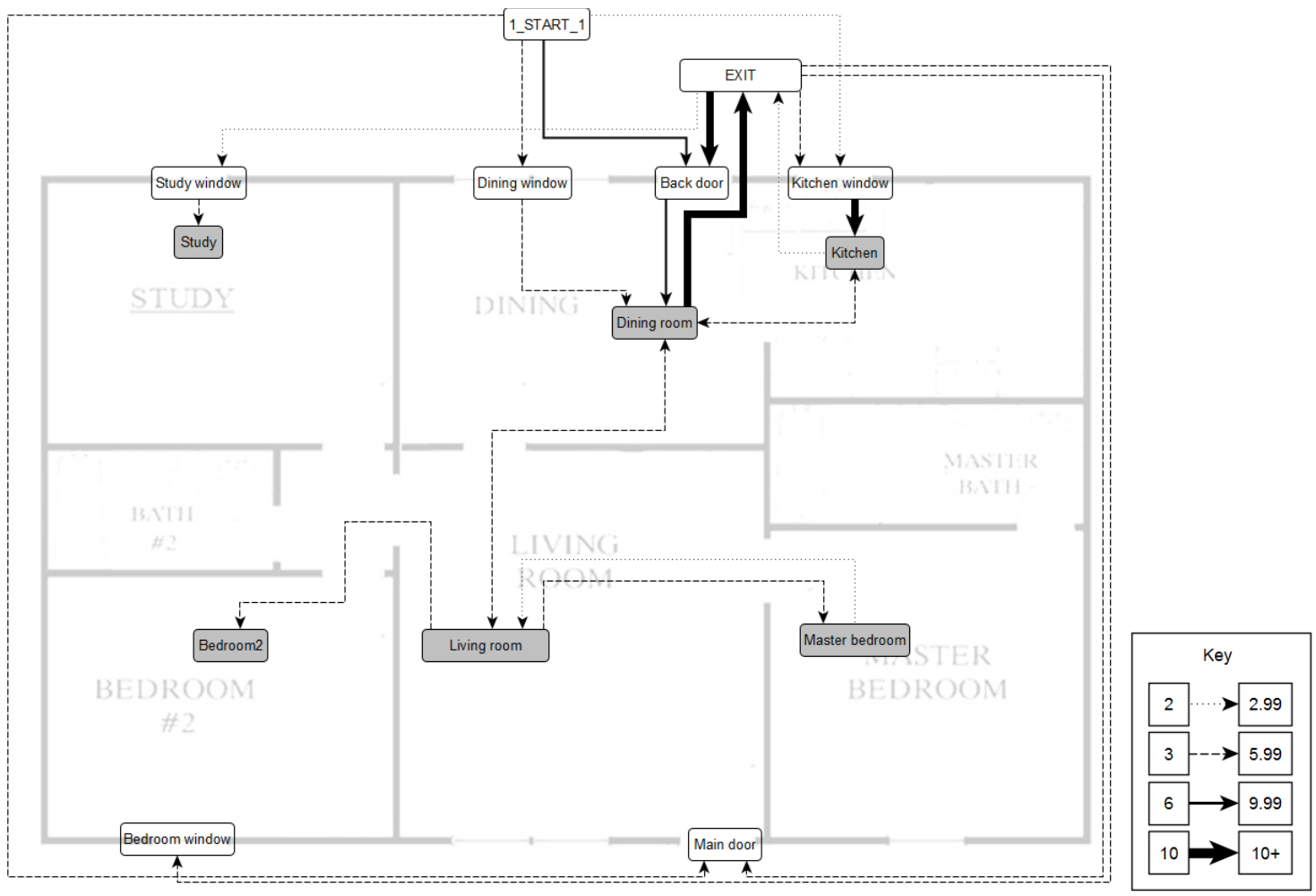

10 Note: The key indicates the standardised residual scores for transitions between behaviours.

11 Thicker lines indicate higher standardised residuals

12

Figure 4 provides the complete Behaviour Tracking map of perceptions of movements

14 around the property and items stolen from each room as burglars moved around. Most 
1 participants perceived that burglars would enter through the back door and go in to the dining

2 room $(n=27, S R=8.49)$. Once in the dining room, silverware was the most likely to be stolen

$3(\mathrm{n}=15, \mathrm{SR}=10.40)$. In the second bedroom (Bedroom \#2), after stealing the Xbox 360, burglars

4 were more likely than chance to steal an iPod $(n=22, S R=20.81)$. Whereas movement into the

5 study was not clearly shown in the previous figure (Figure 3), the current findings clearly show

6 that once in the study the desktop computer $(n=10, S R=13.31)$ and the laptop computer $(n=$

$7 \quad 23, \mathrm{SR}=16.76)$ were most likely to be stolen.

8

9 Figure 3. Full geospatial BSA of movements around the property and items stolen
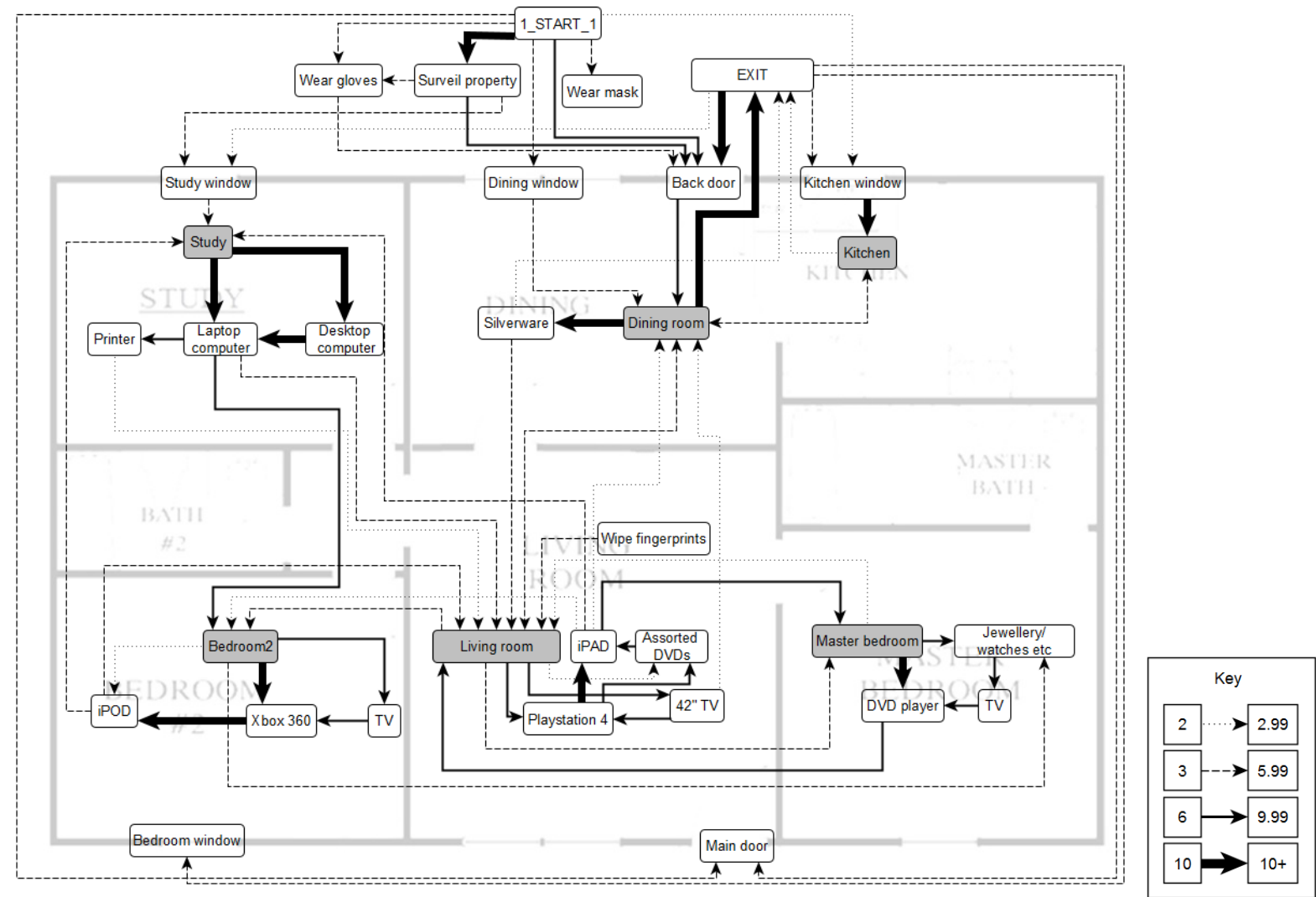

12 Note: The key indicates the standardised residual scores for transitions between behaviours.

13 Thicker lines indicate higher standardised residuals 


\section{Discussion}

The current study provides a novel approach to spatio-temporal investigation,

Behaviour Tracking, which takes Behaviour sequence analysis and maps the movements in a

5 geographically meaningful state space. The aim of Behaviour Tracking is to provide a novel method for crime analysis. This method can, and has, been used in a number of applied contexts;

7 however, to show the method to a wider audience, a perception-based dataset of a residential

8 burglary was used. The example data, aimed at replicating police reports of burglary, were used

9 to illustrate how the method and analyses can be used in real criminal datasets. The use of

10 participant perceptions allowed an open dataset that was not restricted under nondisclosure

11 barriers, and therefore allowed the publication of the method for wider distribution and

12 development. The current analyses can be used in the same manner in real criminal cases as well

13 security issues (like exit routes and pathways of people in the event of emergency evacuations).

14 Although the current dataset used perception based sequences, the findings are

15 consistent with findings in the wider literature (Nee and Taylor, 2000; Wellsmith and Burrell,

16 2005; Homel, Macintyre and Wortley, 2014; van Gelder et al., 2017). For instance, the majority

17 of participants suggested that burglars would enter through the rear of property, which is

18 typically not as visible as the front of the property. This matches rational choice perspective

19 (Cornish and Clarke, 2016) in that burglars are motivated to enter and exit undetected, which

20 participants correctly perceived as shown by the results. Similarly, participants also suggested

21 that smaller items were more likely to be stolen, which matches rational choice theory

22 predictions and previous research that shows burglars steal smaller goods as they are easier to

23 carry and relatively simple to sell on (Nee and Taylor, 2000; Clare, 2011; van Gelder et al.,

24 2017). This previous research outlines the burglar as an expert in their decision-making (Nee and 
1 Ward, 2015), and the overlap of findings in the current research suggest that the participants'

2 perceptions were an accurate representation of real-world behaviours.

The current findings, however, also highlight that many people are fixated on the archetypal forms of burglary. In every case outlined by participants, the simplified sequence was:

5 enter, steal item(s), leave. This is certainly a type of burglary; but, it is not the only type. For

6 example, no participant mentioned destruction of property or other aberrant behaviours. In the

7 current study, participants were told the house was empty - though if people were present, this

8 would add to more complex scenarios and maps, which the method could be used to outline and

9 highlight similarities across repeated offences (Keatley \& Clarke, 2019). For example, in the

10 case of the East Area Rapist /Golden State Killer, the criminal performed a series of similar

11 actions across each crime, Behaviour Tracking could be used to provide clearer outlines of the

12 spatio-temporal similarities between crimes scenes, possibly indicating a similar criminal is

13 responsible.

The current study outlines a key advancement over previous temporal methods of

15 analysis in burglary, such as crime script analysis or standard BSA. The findings indicate not

16 only what behaviours are exhibited in the commission of a crime; but, the location of those

17 behaviours. By including geographic locations in the dataset movements can be spatially as well

18 as temporally located. This is a relatively straightforward and easy development of the BSA

19 method, which has been used in real-world cases. Behaviour Tracking has also been used in real-

20 world applications such as the preparation, attack/abduction location, and disposal of bodies

21 across several homicide cases. This research used locations such as 'indoors' and 'outdoors' as

22 well as killers' modus operandi to show types of behaviours in each location. A further

23 application of the method, related to the current research was to analyse several breaking-and- 
1 entering crimes that resulted in the sexual assault of the female resident inside the property.

2 Victim statements and forensic information were used for these applications, which did not

3 always provide clear progressive steps; however, main patterns of movements and behaviours

4 emerged, and allowed a foundation framework to begin comparing and analysing future cases. In

5 addition to these cases a further pertinent area this research could be developed to assist with

6 crime prevention strategies is in terms of the recent focus on environment planning for terrorist

7 acts and school shootings (Meyer, 2013; Keatley, McGurk and Allely, 2018). If we could begin

8 to map the movements of criminals through buildings, then crime prevention strategies could be

9 developed to reduce the risk or impede the crime commission.

An obvious limitation of the current study was the use of participants' perceptions,

11 rather than real crime data. However, the use of perception-based data did allow for wider

12 dissemination, and therefore allows the method to be published to a wider audience. Given the

13 overlap between results in the current dataset with existing findings on burglary, the results can

14 be taken as proxy for real criminal behaviours, and therefore the application of the Behaviour

15 Tracking to real crime datasets still holds.

For real-world crime data, evidently CCTV data would provide clear behavioural

17 sequences that can be spatially mapped (cell-phone locations may also provide similar types of

18 geographic locations). However, investigations based on witness or suspect statements are often

19 open to biases in memory or forgetting. Clearly, the Behaviour Tracking method will only be as

20 good as the data used; however, this is true for all memory-derived research (Keatley, 2018).

21 Furthermore, as noted, a benefit of the Behaviour Tracking method over free-recall

22 interview/interrogation approaches is that witnesses create a timeline that may trigger memories

23 through seeing gaps, and investigators can begin to build an 'archetypal' sequence from which to 
1 compare witness/suspect statements to assess validity. Therefore, the use of memory recall is not

2 necessarily an unpassable problem for the method of Behaviour Tracking, it simply means that

3 some part of the behavioural chain may be missing. Taking a spatio-temporal approach to

4 analyses may offer investigators an opportunity to see geographical as well as temporal gaps in

5 the information given by suspects or victims/witnesses, and prompt further investigation or allow

6 gaps to be filled with 'most likely' movement chains.

While the current study was evidently made for the purpose of providing a detailed

8 account of the Behaviour Tracking analysis (i.e., step-by-step movements of burglars are not

9 always known), the Behaviour Tracking analysis can take relatively few datapoints (i.e.,

10 movements around a home) and still provide maps. The more detailed the account of a person's

11 spatio-temporal movement, the more fine-detailed the Behaviour Map will be; but, having fewer

12 points does not invalidate the method, it simply means we know less of the step-by-step

13 movements. It may be that integrating Bayesian Models (Oatley and Ewart, 2003; Oatley and

14 Ewart, 2011) into the Behaviour Map may provide a means of 'filling' some of the gaps, such

15 that experts in the area provide input into likely movements. Obviously, in real-world data the

16 opposite fact may be the case: very complex datasets. For example, there may be a lot of extra

17 nodes on the diagram (including: presence of owners at home, interpersonal interactions, [guard]

18 dog, burglar alarms, neighbours etc.). The current research purposefully attempted to reduce the

19 complexity of the maps to provide a clearer output. Real-world data are typically messier and

20 presentations using layered animations provides a better presentation of these more complex

21 maps.

The next major step for Behaviour Tracking is to more fully integrate methods from

23 geographic profiling, so that data concerning geographic locations can be more meaningfully 
1 included and developed. There are a number of overlapping terms used in both BSA and crime

2 pattern theory, such as attractors and hotspots. Attractors in BSA are nodes or clusters of nodes

3 that once individuals move in to, they spiral around and are less likely to move away from (such

4 as addiction leading to crime to pay for more drugs, leading to more drugs consumed and then

5 committing further crimes to pay for more drugs etc.). In crime pattern theory, attractors are

6 geographic areas that criminals are more likely to move towards owing to the increase in

7 opportunities for crime. It may be that attractors in BSA state spaces overlap attractors in crime

8 pattern theory locations. Similarly, hotpots in BSA refer to nodes that multiple Behaviours pass

9 through, acting almost like a bottleneck (Keatley, 2018). In crime pattern theory, hotspots are

10 specific locations where the convergence of key elements in crime pattern theory come together

11 (Wortley and Townsley, 2016). Integrating BSA with concepts and analyses from crime pattern

12 theory and geographic profiling leads to a whole new avenue of research, with potentially very

13 important new areas of research. The Behaviour Tracking technique could also be used to map

14 the development of paraphilic behaviours, as outlined by Arntfield (2017), such that different

15 movements and Behaviours around a property indicate where along a continuum an individual is,

16 with regards development of sexual threats and behaviours.

Finally, within the current analyses, the stealing of items was inextricably linked to the

18 rooms items were found in. However, in real-world burglaries a number of alternative actions

19 can be taken in each room (for instance, destruction of property). Therefore, further analyses

20 could be conducted in which behaviours are 'nested' within rooms. In a wider approach to

21 Behaviour Tracking this would be akin to mapping movements between cities that a criminal or

22 terrorist may take (major level), and then mapping the behaviours within that city (nested levels), 
1 such that we could see at a global level a person moves from City A to City B; but, within those

2 cities a number of sub-behaviours are sequentially performed.

\section{Conclusion}

Crime does not happen in a vacuum, separate from any surrounding temporal or spatial

6 influences. Therefore, recently, researchers have attempted to develop spatial analyses and

7 temporal analyses. The current study is the first to integrate Behaviour Sequence Analysis with

8 spatially meaningful locations, as a foundation for future developments in this area. Behaviour

9 Tracking allows investigations to map the spatial and temporal movements of criminals around

10 various locations (e.g., within a building, or through city streets). This allows the crime

11 commission process to be understood in spatio-temporal sequences. The current dataset provided

12 an example of how burglaries may be investigated and mapped using Behaviour Tracking.

13 Future research and collaborative approaches should apply this method to other crimes and use

14 real-world crime data wherever possible. CCTV data will evidently present some of the best

15 forms of data in terms of clear movements; however, the use of qualitative statements in the

16 current data highlight the versatility of Behaviour Tracking to be used on different datasets. 
${ }^{i}$ Clearly, real-world data is seldom so 'clean'; however, the current paper is meant to outline the methodological approach, therefore, more detailed data were preferable.

ii In other crimes this may be a point at which a suspect is more easily apprehended; or in evacuation scenarios, this could be finding where bottle-necks occur etc.

iii There were no systematic differences between those participants that were Forensic Psychology students, and those that were not. Therefore, the sample was analysed as a whole. An alternative approach could have been to create a set of 'dummy' data (as in Keatley \& Clarke, 2019); however, to provide a somewhat more realistic dataset based on verbal reports (akin to witness statements), we used participants.

iv A floor plan was given to provide some consistency to participants' accounts of crime sequences (otherwise, any number of different properties could be envisioned, and while this would be possible to group and analyse, it was deemed overly complex for the present study). While the floor plan does reduce ecological validity, it does allow for a clearer map to emerge, to show how Behaviour Tracking works. Again, the current article is meant to showcase the Behaviour Tracking method, rather than provide an explanation of burglary, per se.

${ }^{v}$ Although experts in BSA were used in the current study, this was owing to the author team involved. The BSA and Behaviour Tracking method can be conducted by non-specialised researchers, as long as they follow guidelines (see Bakeman \& Gottman, 1986; Clarke and Crossland, 1985; Keatley, 2018).

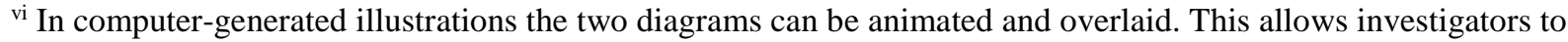
see global-level movements (between rooms, Figure 3), and nested Behaviours within each room (Figure 4). This would be akin to criminals moving between cities or countries (global movements) and actions within each city (nested Behaviours).

vii This is likely a caveat of providing participants with an inventory of each room, a priori; they knew beforehand that the bathrooms provided no items worth stealing. Obviously, in actual crimes, most burglars do not have this foreknowledge. However, this is a limitation of the current data, not the current method. Similarly, real-world data will provide many more nuances and pathways in the dataset (e.g., dogs, people being home etc.). This makes the analyses more complex; but, the basic approach outlined here remains the same. 


\section{References}

Arntfield, M. (2016). “’Money. Armed. Quietly’: A Sociolinguistic Analysis of Criminogenic Prose in Institutional Holdup Notes.” Semiotica, 208(1). 237-258.

Arntfield, M. (2017) Mad City: The True Story of the Campus Murders That America Forgot. New York: Little A Books.

Bakeman, R. and Gottman, J. M. (1986) 'Observing behavior: An introduction to sequential analysis', Cambridge: Cambridge University. doi: 10.1017/CBO9780511527685.

Bakeman, R. and Quera, V. (2011) Sequential analysis and observational methods for the behavioral sciences., Sequential analysis and observational methods for the behavioral sciences. doi: 10.1017/CBO9781139017343.

Caneppele, S. and Calderoni, F. (2013) Organized Crime, Corruption and Crime Prevention: Essays in Honor of Ernesto U. Savona. Springer Science \& Business Media.

Carroll, J. S. and Payne, J. W. (2014) Cognition and Social Behavior. Psychology Press.

Chainey, S. and Ratcliffe, J. (2013) GIS and Crime Mapping, GIS and Crime Mapping. doi: $10.1002 / 9781118685181$.

Clare, J. (2011) 'Examination of systematic variations in burglars' domain-specific perceptual and procedural skills', Psychology, Crime and Law. doi: 10.1080/10683160903025810.

Clarke, D. D. and Crossland, J. (1985) Action systems: An introduction to the analysis of 
complex behaviour. London: Methuen.

Clarke, R. V. G. and Felson, M. (2004) Routine activity and rational choice, Advances in criminological theory; v. 5.

Cornish, D. B. and Clarke, R. V. (1987) 'Understanding crime displacement: an application of rational choice theory', Criminology, 25(4), pp. 933-948. doi: 10.1111/j.17459125.1987.tb00826.x.

Cornish, D. B. and Clarke, R. V. (2016) 'The rational choice perspective', in Environmental Criminology and Crime Analysis: Second Edition. doi: 10.4324/9781315709826.

Ellis, H. E., Clarke, D. D. and Keatley, D. A. (2017) 'Perceptions of behaviours in stranger rape cases: a sequence analysis approach', Journal of Sexual Aggression. doi: 10.1080/13552600.2017.1361618.

Fossi, J. J., Clarke, D. D. and Lawrence, C. (2005) 'Bedroom rape: sequences of sexual behavior in stranger assaults.', Journal of interpersonal violence, 20(11), pp. 1444-66. doi: 10.1177/0886260505278716.

van Gelder, J. L. et al. (2017) 'Virtual Burglary: Exploring the Potential of Virtual Reality to Study Burglary in Action', Journal of Research in Crime and Delinquency. doi: 10.1177/0022427816663997.

Gilmour, N., Hicks, T. and Dilloway, S. (2017) 'Examining the practical viability of internationally recognised standards in preventing the movement of money for the purposes of terrorism: A crime script approach', Journal of Financial Crime, 24(2), pp. 260-276. doi: 10.1108/JFC-04-2016-0027. 
Haelterman, H. (2016) Crime Script Analysis: Preventing crimes against business. Springer.

Homel, R., Macintyre, S. and Wortley, R. (2014) 'How house burglars decide on targets', in Leclerc, B. and Wortley, R. (eds) Cognition and Crime: Offender Decision Making and Script Analyses. Oxford: Routledge, pp. 26-47.

Ivanouw, J. (2007) 'Sequence analysis as a method for psychological research.', Nordic Psychology, 59(3), pp. 251-267. doi: 10.1027/1901-2276.59.3.251.

Keatley, D. A. (2018) Pathways in crime: an introduction to Behaviour Sequence Analysis. London: Palgrave Macmillan.

Keatley, D. A. et al. (2018) 'Using Behavior Sequence Analysis to Map Serial Killers’ Life Histories', Journal of Interpersonal Violence. doi: 10.1177/0886260518759655.

Keatley, D. A., Barsky, A. D. and Clarke, D. D. (2017) 'Driving under the influence of alcohol: a sequence analysis approach', Psychology, Crime and Law, 23(2), pp. 135-146. doi: 10.1080/1068316X.2016.1228933.

Keatley, D. A., McGurk, S. and Allely, C. S. (2018) 'Understanding School Shootings with Crime Script Analysis', Deviant Behavior.

Lawrence, C., Fossi, J. and Clarke, D. (2010) ‘A sequential examination of offenders' verbal strategies during stranger rapes: The influence of location.', Psychology, Crime \& Law, 16(5), pp. 381-400. doi: 10.1080/10683160902754964.

Leclerc, B. and Wortley, R. (2013) Cognition and crime: Offender decision making and script analyses, Cognition and Crime: Offender Decision Making and Script Analyses. doi: $10.4324 / 9780203083482$. 
Leclerc, B. and Wortley, R. (2014) Cognition and crime: Offender decision making and script analyses, Cognition and Crime: Offender Decision Making and Script Analyses. Oxford: Routledge. doi: 10.4324/9780203083482.

Leclerc, B., Wortley, R. and Dowling, C. (2016) 'Situational Precipitators and Interactive Forces in Sexual Crime Events Involving Adult Offenders', Criminal Justice and Behavior. doi: $10.1177 / 0093854816660144$.

Meyer, S. (2013) 'Impeding lone-wolf attacks: Lessons derived from the 2011 Norway attacks', Crime Science. doi: 10.1186/2193-7680-2-7.

Nee, C. and Taylor, M. (2000) 'Examining burglars' target selection: Interview, experiment or ethnomethodology?', Psychology, Crime and Law. doi: 10.1080/10683160008410831.

Nee, C. and Ward, T. (2015) 'Review of expertise and its general implications for correctional psychology and criminology', Aggression and Violent Behavior. doi: 10.1016/j.avb.2014.12.002.

Oatley, G. C. and Ewart, B. W. (2003) 'Crimes analysis software: "Pins in maps”, clustering and Bayes net prediction', Expert Systems with Applications. doi: 10.1016/S0957-4174(03)00097-6.

Oatley, G. and Ewart, B. (2011) 'Data mining and crime analysis', Wiley Interdisciplinary Reviews: Data Mining and Knowledge Discovery. doi: 10.1002/widm.6.

Osborne, J, R. and Capellan, J, A. (2017) 'Examining active shooter events through the rational choice perspective and crime script analysis', Security Journal, 30(3), pp. 880-902.

Pastra, K., Saggion, H. and Wilks, Y. (2003) 'SOCIS: Scene of Crime Information System'.

Ratcliffe, J. (2010) ‘Crime Mapping: Spatial and Temporal Challenges', in Handbook of Quantitative Criminology. doi: 10.1007/978-0-387-77650-7_2. 
Taylor, O., Keatley, D. A. and Clarke, D. D. (2017) 'A Behavior Sequence Analysis of Perceptions of Alcohol-Related Violence Surrounding Drinking Establishments', Journal of Interpersonal Violence.

Taylor, P. J. et al. (2008) 'Analysing forensic processes : Taking time into account', Issues in Forensic Psychology, pp. 43-56.

Team, R. (2013) 'R Development Core Team', R: A Language and Environment for Statistical Computing, 55, pp. 275-286.

Wellsmith, M. and Burrell, A. (2005) 'The influence of purchase price and ownership levels on theft targets: The example of domestic burglary', British Journal of Criminology. doi: 10.1093/bjc/azi003.

Wortley, R. (2016) 'Situational precipitators of crime', in Environmental Criminology and Crime Analysis: Second Edition. doi: 10.4324/9781315709826.

Wortley, R. and Townsley, M. (2016) Environmental criminology and crime analysis: Second edition, Environmental Criminology and Crime Analysis: Second Edition. doi:

$10.4324 / 9781315709826$. 